\title{
NATIONALE EN INTERNATIONALE MAATREGELEN TEN BEHOEVE VAN DE VOLLEDIGE WERKGELEGENHEID.
}

\author{
door Prof. Dr. J. Tinbergen.
}

\section{Inleiding.}

Door de Economische en Sociale Raad van de Verenigde Naties is een rapport gepubliceerd, samengesteld door een groep van deskundigen, aangewezen door de Secretaris-Generaal, betreffende maatregelen voor de volledige werkgelegenheid.

De groep was als volgt samengesteld:

Professor J. M. Clark, bekend door zijn werk op het gebied van conjunctuuronderzoek en conjunctuurpolitiek;

Professor A. Smithies (Harvard);

Dr. P. Uri, van het commissariaat-generaal van het Plan, Parijs;

Voorzitter: E. R. Walker (Australië).

Het rapport, getiteld: National and International Measures for Full Employment, bestaat uit drie delen; het eerste en tweede is van analytisch karakter, terwijl het derde deel de aanbevolen maatregelen bevat. $\mathrm{Er}$ is een nabeschouwing van de hand van Professor Clark, waarop wij nog terugkomen.

\section{Nationale maatregelen.}

Aangezien de analyse zorgvuldig is afgestemd op de later vermelde maatregelen, kan voor het doel van dit artikel worden volstaan met een weergave van het derde deel. De aanbevolen maatregelen worden gesplitst in nationale en internationale. Ten aanzien van de nationale mogen $\mathrm{zij}$ als volgt worden samengevat:

1. elke regering make een door haar aanvaarde norm bekend t.a.v. het toelaatbare werkloosheidspercentage;

2. zij kondige een uitvoerig programma van haar politiek aan, met name fiscale, monetaire, investerings-, loon- en prijspolitiek ter bevordering van de volledige werkgelegenheid 
3. zij kondige aan een eigen systeem van compenserende maatregelen, voorbereid voor automatische toepassing, indien het onder 1 bedoelde werkloosheidspercentage voor ten minste drie maanden met een van te voren bepaald bedrag worden overschreden;

4. zij kondige bepaalde maatregelen aan, die zij van plan is uit te voeren tot stabilisering van het prijsniveau.

Deze vier punten worden vervolgens uitvoerig toegelicht.

1. Wat de aanvaarding van een norm betreft, wordt gewezen op het nut daarvan enerzijds bij de te voeren politiek zelf (zie punt 3) en ten tweede om goed duidelijk te maken dat het haar ernst is met deze politiek. De deskundigen zijn overigens van mening dat geen uniforme gedragslijn ten deze kan worden voorgeschreven.

In hoogontwikkelde landen zal het beste een werkloosheidspercentage kunnen worden gekozen met een zekere marge, bv. $2-4 \%$ of $3-5 \%$ van het aantal loontrekkenden (dus niet van de beroepsbevolking; een punt waarover b.v. Beveridge zich niet duidelijk uitlaat). Ook de hoogte van het percentage kan van land tot land variëren i.v.m. grotere seizoenwerkloosheid e.d. Gedeeltelijke werklozen behoren te worden meegeteld (zij het met overeenkomstig geringere wegingscoëfficiënt).

Voor minder -ontwikkelde landen zou vermoedelijk beter kunnen worden uitgegaan van de doelstelling uitgedrukt in het aantal personen dat in de industrie werk vindt, welk getal dan een behoorlijk stijgend tempo moet vertonen.

2. De gehele op de volledige werkgelegenheid gerichte politiek kan worden beschouwd als een onderdeel van de algemene welvaartspolitiek en zal enigszins kunnen afhangen van de algemene aard der door het land gevolgde politiek. In sommige landen zal een meer gedetailleerd ingrijpen in het economisch leven plaats vinden dan in andere landen en zal dienovereenkomstig een meer directe politiek kunnen worden gevoerd, met name wanneer een groot gedeelte van het bedrijfsleven in de publieke sector ligt. De in dit rapport opgesomde maatregelen zijn vooral bedoeld voor landen die in hoofdzaak het particulier initiatief hebben aanvaard als beginsel voor het economisch leven. 
De volgende onderdelen van te volgen politiek worden afzonderlijk genoemd:

a. Van groot belang wordt de fiscale politiek geacht. In een tijd van depressie kan men deze of wel aanwenden door verlaging der belasting, of wel door verhoging der uitgaven. Dit hangt af van de omvang van de overheidshuishouding. Gepleit wordt door een stelsel van variabele belastingen, waarbij aan de eventuele technische moeilijkheden niet veel aandacht wordt besteed: men gaat er kennelijk van uit dat deze kunnen worden overwonnen.

Bijzondere betekenis wordt gehecht aan het toekennen van zg. „automatische stabilisatoren", zoals bepaalde maatregelen van sociale zekerheid, die vanzelf in een depressie leiden tot een hogere uitkering, bv. wegens werkloosheid.

b. Daarnaast is het ook mogelijk de particuliere investeringen te beïnvloeden. Men kan ze stimuleren door credietfaciliteiten of door speciale belastingmaatregelen. Men kan ze beperken door credietbeperking, contrôle op de emissies of in zeldzame gevallen door toewijzing van grondstoffen. Van betekenis wordt ook geacht een in samenwerking met de particuliere industrie op te stellen investeringsprogramma op lange termijn, met name voor de zware industrie en de energievoorziening.

c. De openbare investeringen kunnen in het bijzonder tot onderwerp van regulering worden gemaakt wanneer een grote openbare sector van het bedrijfsleven aanwezig is. Een gecoördineerd investeringsprogramma voor deze sector wordt dan ten zeerste aanbevolen. Landen waar practisch alleen de openbare werken door de overheid worden verzorgd, zullen het in een politiek van compenserende openbare werken moeten zoeken. Hierbij moet in het bijzonder worden getracht een goede samenwerking met de lagere publiekrechtelijke lichamen te verkrijgen.

d. Sommige meer ontwikkelde landen zullen er de voorkeur aan geven de investeringen zo stabiel mogelijk te doen verlopen. Daar zal men dan moeten trachten de consumptie te beïnvloeden, hetgeen kan geschieden door belastingmaatregelen, maatregelen van sociale wetgeving, onderwijs, gezondheidszorg, enz.

e. Al deze maatregelen zullen belangrijke steun kunnen ondervinden van de, internationale samenwerking op het terrein van de werkgelegenheidspolitiek, waardoor minder belangrijke 
schommelingen in de werkgelegenheid zijn te verwachten dan anders het geval zou zijn geweest.

f. Tenslotte is stabilisatie van het landbouwinkomen gewenst door stabilisatie van de prijzen van landbouwproducten op de wereldmarkt, zoals bv. door de tarweovereenkomst geschiedt.

3. Het grote belang van automatische tegenmaatregelen is dat het niet steeds aan het initiatief der regeringsorganen behoeft te worden overgelaten of men wel de juiste werkgelegenheidsmaatregelen neemt. Vandaar de uitdrukkelijke aanbeveling, dat wanneer de werkgelegenheid drie maanden achtereen met een van te voren vastgesteld bedrag bij de gestelde norm achterblijft, automatisch bepaalde maatregelen volgen. Deze kunnen dan in de eerste plaats bestaan uit een systeem van variabele belastingen. Men stelt zich daarbij voor dat er twee alternatieve belastingtarieven bestaan, het heersende en een lager, waarvan dan in het genoemde geval het laagste in werking treedt. Dit kan ofwel t.a.v. de inkomstenbelasting worden toegepast, ofwel t.a.v. de premies van de sociale verzekering, of tenslotte t.a.v. de omzetbelasting. Daarnaast is het evenzeer denkbaar, dat men de premies van de sociale verzekering niet langer int en zelfs vervangt door uitkeringen. Ook is het in sommige landen mogelijk. een gunstige tegeninvloed te oefenen door het deblokkeren van oorlogsbesparingen of door het in versneld tempo uitkeren van oorlogsschadevergoedingen. Deze laatste maatregelen zouden voor Nederland bijzondere mogelijkheden bieden.

De Commissie spreekt zich ook uitdrukkelijk uit voor een automatische openbare-werkenpolitiek. $Z$ ij vreest echter dat deze in sommige landen onvoldoende snel zal reageren, om welke reden zij op de andere hiervoor genoemde mogelijkheden wijst.

4. De stabilisatie der prijzen, met name het voorkomen van een inflatoire prijsontwikkeling, kan nodig zijn indien door onvoorziene omstandigheden de vraag sterker toeneemt dan gewenst is. Men denke in dit verband aan de droogte van het afgelopen jaar in Frankrijk en de nieuwe handelsovereenkomst met Duitsland, die de vraag naar Nederlandse producten sterk hebben doen toenemen. Tegen een inflatoire prijsontwikkeling is ofwel een kwalitatieve ofwel een kwantitatieve credietcontrôle mogelijk, ofwel een contrôle op voorraden en een rechtstreekse prijsbeheersing. Wanneer voorts, zo stelt het rapport, door een 
sterkere stijging van de lonen dan overeenkomt met de arbeidsproductiviteit, de prijzen gaan stijgen, moet er voor gewaakt worden dat, zulke prijsstijgingen niet optreden. Wellicht had moeten worden toegevoegd dat zodanige loonstijgingen, behalve tot een zeer gering percentage, ook niet gewenst zijn.

Op dit punt gaat echter ook nog het memorandum van Professor Clark persoonlijk in, waarop aan het einde van dit artikel wordt teruggekomen.

5. Dit alles vergt geen wijziging van het politieke systeem, doch wel een aanpassing van de wetgevingsprocedure, de organen der administratie en de statistiek. Het is noodzakelijk dat een en ander met spoed geschiedt, waarbij in het bijzonder de verhouding tot de lagere publiekrechtelijke lichamen van belang is.

De regeringen moeten ten behoeve van de werkgelegenheid beschikken over een periodieke economische analyse van de ontwikkeling. De verantwoordelijkheid voor de volledige werkgelegenheid moet geconcentreerd worden in de daartoe geëigende orgaan, dat over voldoende personeel beschikt. De statistiek moet o.m. de voornaamste samenvattende cijfers kunnen verschaffen, die de totale vraag naar goederen en diensten bepalen, een desideratum, waaraan in het laatste halve jaar door het Centraal Planbureau en het Centraal Bureau voor de Statistiek is voldaan in de vorm van het voorbereiden van een algemene consumptie-index en een algemene investerings-index. Het rapport noemt niet de consumptie, maar de besparingen, welke naar mening van steller dezes echter minder gemakkelijk zijn vast te stellen dan de consumptie.

\section{Internationale maatregelen.}

Het rapport erkent terecht dat een politiek van volledige werkgelegenheid een op dit punt nauwe internationale samenwerking eist. De internationale maatregelen hebben speciaal tot doel:

1. het evenwicht te herstellen in het internationale goederenen dienstenverkeer;

2. een stabiele stroom van internationale investeringen te creeren, die het mogelijk maakt de weinig ontwikkelde gebieden op een hoger economisch peil te brengen; 
3. het opkomen van nieuwe verstoringen in het internationale handelsverkeer te beletten.

Deze maatregelen worden wederom nader uitgewerkt.

1. Veel betekenis wordt wederom gehecht aan een programma, dat van te voren bekend gemaakt wordt en zo wordt van landen met een deficit op hun betalingsbalans verlangd, dat $z \mathrm{ij}$ verklaren met welk bedrag zij de bedoeling hebben hun exporten te verhogen of hun importen te verlagen. Van landen met een overschot op de betalingsbalans wordt verlangd, dat $z i j$ verklaren met welk bedrag zij de bedoeling hebben hun importen te verhogen, dan wel door het verstrekken van leningen het evenwicht willen herstellen. Veel belang wordt gehecht aan een analyse en een vergelijking van deze doelstellingen en onderhandelingen en wederzijdse raadpleging daaromtrent.

Daarnaast wordt vastgesteld dat deficit-landen de verplichting hebben om interne inflatoire krachten, die eventueel zouden bestaan, te bestrijden en om hum wisselkoersen aan te passen, ten einde hun exporten omhoog te brengen. De voornaamste verplichtingen van overschot-landen zijn, er voor zorg te dragen dat een daling van hun export niet gepaard gaat met verlaging der interne productie en dat de importen kunnen worden verhoogd door het wegnemen van handelsbelemmeringen.

Aanbevolen wordt de oprichting van een adviescommissie van deskundigen, verantwoordelijk aan de Ecosoc en optredende in nauwe samenwerking met de gespecialiseerde organen ten einde:

a. een gedetailleerde procedure uit te werken voor de formulering van het programma en de coördinatie der nationale maatregelen;

b. het initiatief te nemen de regeringen te wijzen op vraagstukken die tijdens deze coördinatie zullen opkomen;

c. met geregelde tussenpozen te rapporteren aan de Ecosoc over de resultaten betreffende urgente vraagstukken, die de aandacht van de Verenigde Naties of de speciale organen vergen.

2 Ter bevordering van een stabiele stroom van internationale investeringen wenst de Commissie een wijziging aangebracht te zien in de statuten van de Internationale Bank voor Herstel en Ontwikkeling, daarheen gaande dat de Bank het recht krijgt 
aan de ene kant van bepaalde regeringen te lenen en aan de andere kant kapitalen te verstrekken aan andere regeringen, niet alleen voor speciale projecten, doch voor de ontwikkeling van hun landen in het algemeen. Daartoe moet naar hun mening (a) een nieuwe afdeling aan de Bank worden toegevoegd, die (b) volkomen gescheiden gehouden van de overige afdelingen geen gebruik mag maken van het kapitaal van de Bank, doch (c) een speciaal fonds moet inrichten uit leningen van kapitaalexporterende landen.

Wat de betrekkingen van de Bank met de regeringen dezer laatste landen aangaat wordt voorgesteld dat:

I) geleend wordt op lange termijn tegen dezelfde voorwaarden als deze regeringen op hun eigen markt kunnen bedingen;

II) de omvang waarin de Bank leent van de regeringen in overeenstemming moet zijn met de gedachte, dat hun kapitaalexport gestabiliseerd wordt;

III) de Bank in het algemeen de aldus uitgegeven obligaties weer behoort in te kopen naar mate zij van de credietnemende regeringen terugbetaling ontvangt. Indien echter het ontwikkelingsprogramma naar de mening van de Bank gevaar zou lopen, zou hiervan kunnen worden afgeweken;

IV) de leningen beschikbaar zouden moeten worden gesteld in de valuta van het kapitaalexporterende land en in het algemeen gesproken overal zouden moeten kunnen worden aangewend;

V) verliezen niet kunnen worden afgeschreven op het kapitaal van de Bank; voorzover de' reserves van de nieuwe afdeling niet voldoende zijn, zullen zij moeten worden gevonden door een proportionnele afschrijving op de uitstaande obligaties.

Ten aanzien van de betrekkingen van de Bank tot de kapitaalvragende regeringen wordt voorgesteld dat:

I) de Bank slechts leent aan de centrale regeringen van die landen;

II) deze leningen geschieden op basis van het algemene ontwikkelingsprogramma dier landen waarvan de criteria moeten bestaan in hun effect op nationaal inkomen, belastingen, kapitaal en exportcapaciteit;

III) de regeringen speciale kapitaalsbegrotingen dienen op te stellen waarin de financiering van hun ontwikkelingsprogramma's is neergelegd; 
IV) aan alle landen dezelfde rente in rekening zal worden gebracht, evenals dat tegenwoordig het geval is, welke rente een marge van $1 \%$ laat ter dekking van de kosten en het risico van de Bank;

V) de aflossing moet overeenstemmen met de verplichtingen van de Bank voor haar eigen leningen. (Dit schijnt onvoldoende duidelijk, aangezien men eerst stelde, dat de aflossingen zullen geschieden al naar mate de terugbetalingen binnenkomen.)

3. Ten einde de internationale handel te stabiliseren dient, naar de mening van de deskundigen, in de eerste plaats te worden gestreefd naar een zo nauwkeurig mogelijke uitvoering van de nationale programma's van stabilisatie. Gezien echter de grote risico's voor andere landen gelegen in het falen van de werkgelegenheidspolitiek van één enkel land, dienen daarnaast nog voorzorgen te worden genomen ter voorkoming van de internationale verspreiding van een depressie. Een der mogelijkheden bestaat in het handhaven van de importen in het falende land door het opslaan van voorraden. Een tweede mogelijkheid bestaat in een verstrekkend voorstel, dat de Commissie toevoegt aan haar programma en dat van elke regering vraagt de verantwoordelijkheid te aanvaarden, binnen het kader van een internationaal schema de monetaire reserves van andere landen te zullen aanvullen. Dit zou moeten geschieden in de mate waarin de uitputting dezer reserves gepaard gaan met een afneming van hun eigen importen, foorzover deze is veroorzaakt door een algemene daling in de vraag naar goederen en diensten in hun eigen land. De Commissie meent dat de aanvaarding van een zodanige regeling de belangrijkste bijdrage zou zijn, die in de internationale sfeer zou kunnen worden gemaakt ter bescherming van de wereldhuishouding tegen de verspreiding van periodieke deflatoire invloeden.

$\mathrm{Bij}$ de formulering van hun aanbevelingen hebben de deskundigen getracht een internationale regeling te ontwerpen, die voldoet aan zes fundamentele eisen:

1. de regeling voorziet in het aanvullen van de internatonale reserves, doch moet niet leiden tot enige toeneming der reserves;

2. zij mag niet worden misbruikt ten einde de invoer der daarvan profiterende landen te verhogen; 
3. er moet worden voorzien in een schema van terugbetaling zodra de omstandigheden dit toelaten;

4. $z$ ij mag niet het normale proces van aanpassing aan de internationale structuur vertragen;

5. zij moet zijn gebaseerd op eenvoudige, duidelijke en vastomlijnde beginselen, ten einde haar werking zo soepel mogelijk te maken en ten einde haar werking in de toekomst bij voorbaat duidelijk te maken;

6. de regeling moet worden uitgevoerd door een daartoe geeigende internationale instelling.

Als deze instelling wordt het Internationale Monetaire Fonds voorgesteld, dat daartoe een statutenwijziging moet ondergaan. Volgens de voorgestelde nieuwe statuten zal het volgende gelden:

a. Indien in enig jaar de waarde van de invoer van goederen en diensten voor een bepaald land daalt ten gevolge van de daling van de totale vraag in dat land en deze daling is niet volledig gecompenseerd door een teruggang in de waarde van de uitvoer, dient dit land bij het Fonds een bedrag te deponeren, in zijn eigen valuta, gelijk aan de daling in zijn importoverschot in het betrokken jaar in vergelijking tot een basisjaar.

b. Het basisjaar is in het algemeen het voorafgaande jaar. Slechts wanneer dit een jaar van te grote werkloosheid is, worden andere met name genoemde maatstaven aangelegd.

c. Een land kan van de verplichting onder $a$ worden vrijgesteld, indien ter beoordeling van het Fonds kan worden aannemelijk gemaakt, dat de daling in zijn invoer aan andere factoren moet worden toegeschreven dan aan een algemene daling van de vraag.

d. Het Fonds heeft het recht het verkregen deposito om te zetten in andere valuta. Enig land dat de valuta van het deponerende land wenst aan te kopen, moet dit aan het Fonds kenbaar maken niet later dan in de achtste maand van het kalenderjaar. Het aankopende land is gerechtigd de valuta van het deponerende land aan te kopen tot een bedrag niet overschrijdende de daling van zijn uitvoeroverschot t.o.v. het deponerende land, vergeleken met het basisjaar. Een regeling wordt voorgesteld voor het geval dat het Fonds over onvoldoende valuta van dat land beschilkt. 
e. De valuta van de aankopende landen dient door het Fonds ter beschikking te worden gesteld van het deponerende land. Hiertoe dient het deponerende land de aanvraag iedere zes maanden bij het Fonds in te dienen, waarbij niet meer kan worden aangevraagd dan overeenstemt met de daling van zijn monetaire reserves gedurende een voorafgaande periode van 6 maanden.

Bij de berekening van de achteruitgang van de monetaire reserves dient buiten beschouwing te worden gelaten de normale toeneming van reserves ten gevolge van nieuwe goudproductie. Deze normale toeneming moet worden berekend op de basis van het aandeel van het deponerende land in de wereld-goudreserves.

Hiermede zijn de voorstellen van de Commissie in hoofdzaak weergegeven. Zoals gezegd wordt het rapport gevolgd door een persoonlijke memorandum van Professor Clark, waarmede overigens de andere leden van de groep in het Voorwoord verklaren, zich geheel te kunnen verenigen.

Uit dit memorandum blijkt dat de heer Clark het rapport mede heeft getekend, omdat hij gelooft dat in het tegenwoordige tijdsgewricht het risico van een onjuiste werkgelegenheidspolitiek zwaarder moet wegen dan de risico's, die ongetwijfeld aanwezig $z \mathrm{jjn}$ in het toepassen van sommige der hierboven uileengezette maatregelen.

Hij blijkt van mening te zijn dat de in het rapport gegeven analyses en aanbevelingen in het bijzonder op één punt onvolledig zijn, waarop hij nog wat verder ingaat. Dit punt betreft de hoogte van het loonpeil. Hij wijst er op dat dit voor de werkgelegenheid eveneens van betekenis is, al heeft er steeds meningsverschil bestaan of men ter bevordering van de werkgelegenheid de lonen moet doen stijgen dan wel dalen. Persoonlijk is hij van mening dat het wel eens zou kunnen zijn, dat in de ene situatie het ene en in een andere situatie het andere nodig zou kunnen zijn, aangezien immers de twee voornaamste werkingen, die van het loonpeil uitgaan op de werkgelegenheid elkaar bijna compenseren. Een loonsverhoging immers betekent aan de ene kant een stijging van de kosten en prijzen, die op de afzetmogelijkheden ongunstig werken, en aan de andere kant stijging van de koopkracht der werkende arbeiders, die op de 
afzetmogelijkheden gunstig werken. Zodoende is het duidelijk dat de juiste keuze van het loonniveau evenzeer een vereiste kan zijn voor een goede werkgelegenheidspolitiek.

\section{Enige voorlopige kanttekeningen.}

Vooropgesteld worde, dat zelden een zo belangrijk rapport is verschenen, in het bijzonder omdat het niet is een verzameling van algemeenheden of gemeenplaatsen, doch een zeer concreet en in sommige opzichten gedurfd stuk. Wij menen dat het daarbij op talrijke punten een gelukkige greep heeft getoond, al zal het nog heel wat moeite kosten een aantal van deze punten te verwezenlijken. Het rapport heeft reeds in elk geval de nuttige functie vervuld de publieke opinie op deze punten te hebben gewezen.

Een aantal der behandelde onderwerpen is sinds enige tijd in beginsel al wel aanvaard. Het rapport wil deze voorstellen echter vaster verankeren. Daartoe kiest het de volgende wegen:

1. Er moeten, zoals wij hebben gezien, normen en doelstellingen in het openbaar worden gesteld, zowel in de binnenlandse als in de internationale werkgelegenheidspolitiek. De tegenzin van vele regeringen zich te binden, zal het niet gemakkelijker maken. ze daartoe te krijgen. Toch is het duidelijk dat er een zeer groot belang mee gemoeid zou zijn en wij menen niettemin te moeten aanbevelen, dat de voorstellen van het rapport in deze worden gevolgd. Men verhele zich daarbij intussen niet, dat deze normen wel eens zouden kunnen blijken onverenigbaar te zijn met sommige andere desiderata, die bij bepaalde groepen en regeringen bestaan. Het handhaven van een hoge werkgelegenheid is niet verenigbaar met elk willekeurig peil van kosten en dus van inkomen.

2. Er. moeten daarnaast zekere automatismen worden ,ingebouwd" in ons economisch bestel: als voorbeelden zijn reeds genoemd automatische belastingwijzigingen, wijzigingen in de premies en uitkeringen van de sociale verzekeringen en uitgaven voor publieke werken. Omtrent de mogelijkheden hiertoe lopen de meningen uiteen. De technici op belastinggebied bv. zien velerlei bezwaren. Evenzo de technici op het gebied van sociale verzekeringen en openbare werken. Wij moeten er echter voor zorgen, dat het hier niet een kaatsen van de bal wordt door elk dezer groepen naar de andere. Deze moeilijkheden zijn er om overwonnen te worden en ieder der genoemde groepen zal haar uiterste best moeten doen 
om een bijdrage te leveren tot de oplossing van dit vitale vraagstuk, dat de fundamenten van ons bestaan raakt.

3. Er is samenwerking nodig op velerlei niveau: internationaal en nationaal. Wat de laatste betreft denk ik in het bijzonder aan samenwerking met lagere publiekrechtelijke lichamen, die in ons land ook teeds enige keren is besproken. De samenwerking vereist natuurlijk ongeveer gelijk gerichte gedachten. T.o.v. dit punt is gelukkig door de economische wetenschap reeds het een en ander bereikt. De publieke opinie is daarbij begrijperlijkerwijze ten achter. Veel verdere voorlichting is daarom nodig, ook in populaire vorm. De samenwerking met de lagere publiekrechtelijke lichamen is wellicht ook door een verder automatisme te vergemakkelijken en zeker door het openbaar aanvaarden van zekere normen. Men kan hierbij denken aan bepaalde schalen van belasting en subsidiëring, waardoor de lagere publiekrechtelijke lichamen te voren weten, waaraan zij toe zijn en zij er belang bij hebben om vrijwillig aan de stabilisatie mede te werken.

Wat de samenwerking op internationaal terrein betreft, zal men wel moeten leren van de ervaring, die te dien aanzien in de laatste jaren is opgedaan. Het is gebleken moeilijk te zijn dit te doen op de wijze, waarop de schrijvers van het rapport de samenwerking wensen tot het overwinnen van de structurele onevenwichtigheden in het internationale handelsverkeer. Hier toch stellen zij voor, dat elk land bepaalde doelstellingen bekend maakt t.a.v. de verbeteringen van zijn betalingsbalans en dat deze doelstellingen vervolgens onderwerp vormen van een gedachtewisseling. Naar mijn mening zal het verstandig zijn, dat men daarbij ook op de tafel heeft liggen een alternatief voorstel, uitgewerkt door een deskundig internationaal secretariaat en waarin getracht is de aandelen vast te stellen, die redelijkerwijze door ieder land in de oplossing van het vraagstuk moeten worden geleverd. Heeft men een dergelijk voorstel niet op tafel, dan dreigen de discussies zeer lang en ondoelmatig te worden. Hierdoor wordt het nut van een dergelijke centrale instelling onderstreept, waarvan wij er overigens verschillende bezitten, die slechts behoeven te worden ingeschakeld. Tevens zou men in zulke aangelegenheden niet steeds met unanieme beslissingen moeten willen werken.

Verstrekkend zijn de twee voorstellen t.a.v. de Interbank en het Interfund. Vooral het laatste, dat is te kenschetsen als een poging tot het organiseren van de "doorstroming" van de inkomens, ana- 
loog met wat te dien aanzien de taak is der nationale conjunctuurpolitiek. Daar wordt aanbevolen dat door lenen of belasten van hen, die hun inkomens niet doorgeven, een gedeelte daarvan in handen geraakt van de overheid, die het zal doorgeven. Hier wordt voorgesteld, dat door het lenen van landen, die hun inkomens niet doorgeven bereikt wordt, dat bedoelde bedragen in handen komen van landen, die ze wel zullen doorgeven. Het is inderdaad een algemeen belang van alle betrokken landen dat de "doorstroming" aldus bevorderd wordt. Er zullen ongetwijfeld nog vele technische punten bij moeten worden bekeken. Eén punt dat bv. niet duidelijk is, is of de terugbetalingen steeds mogelijk zijn. Het is echter vanzelfsprekend dat men daartoe de eis stelt. Wanneer de structurele ontwikkeling sterk in het nadeel van een bepaald land zou zijn, zou dit laatste wel eens in de onmogelijkheid kunnen komen verkeren van het Fund geleende bedragen terug te betalen. Hier zullen echter speciale maatregelen nodig zijn, die niet aan het thans voorgestelde moeten worden gekoppeld.

Bij deze enkele kanttekeningen wil ik het laten. $Z_{i j}$ zijn slechts bedoeld ter inleiding van een gedachtenwisseling, die in vele opzichten dieper zal moeten gaan. 